\title{
Aircrew exposure on board a subsonic aircraft studied with complex dosimetric sets 1
}

\author{
F. SPURNÝ*, I. VOTOČ́KOVÁ*, J.F. BOTTOLLIER-DEPOIS**
}

(Manuscrit reçu le 10 mai 1995, révisé le 10 août 1995)

ABSTRACT Radiation fields on board a subsonic aircraft have been studied using a complex set of measuring instruments $i$.e. tissue equivalent proportional counter (TEPC), neutron remmeter, environmental radiation dose rate meter, thermoluminescent detectors (TLDs), track etch detectors (TEDs) and bubble damage neutron detectors (BDNDs). The measurements have been realised on board the airbus A310-300 durign the flights Prague-Montreal and Montreal-Prague, in February 1995. The results obtained are presented, analysed and discussed both from the point of view of the detector responses and the general exposure levels.

RÉSUMÉ Le champ de rayonnement à bord des avions subsoniques a été étudié au moyen d'un ensemble complexe de dosimètres (compteur proportionnel équivalent au tissu (CPET), "remmeter" pour les neutrons, détecteurs thermoluminescents (DTL), détecteurs solides de traces (DST), et détecteurs à bulles). Les mesures ont été réalisées à bord d'un airbus $\mathbf{A} 310-300$ pendant des vols Prague-Montréal et Montréal-Prague au cours du mois de février 1995. Les résultats obtenus sont présentés, analysés et discutés tant du point de vue des réponses des différents dosimètres que du niveau d'irradiation générale.

\section{Introduction}

ICRP 60 recommendations [8] propose to decrease the annual limit of dose equivalent for the general public to $1 \mathrm{mSv}$. Due to cosmic radiation on board most civil aircraft members regularly receive an exposure exceeding this limit; ICRP 60 recommends therefore to include them among workers occupationally exposed to radiation. Many studies have been carried out since 1991 to improve the knowledge concerning the quantitative and qualitative aspects of aircrew exposure $[6,10,13,16]$.

\footnotetext{
1 Studies partially supported through the EC project FI3P-CT92-0026.

* Department of radiation dosimetry, NPI AS CR, CZ 180 86, Prague 8, République Tchèque.

** Institut de protection et de sûreté nucléaire (IPSN), DPHD/Service de dosimétrie, Centre d'Etudes de Fontenay aux Roses, BP 6, F-92265 Fontenay aux Roses Cedex.
} 
This work presents and analyses the results of studies performed on board subsonic aircrafts using a complex set of measuring instruments (TEPC, remmeters, environmental radiation dose rate meters, TLDs', track etch and bubble damage neutron detectors, ...) during long haul flights in February 1995.

\section{Material and methods}

\subsection{Dosemeters used}

\section{a) Active measuring equipment}

The sensor of the NAUSICAA equipment $[3,11]$ is a cylindrical low gas pressure tissue equivalent proportional counter. Its sensitive volume is filled with a propane-based tissue equivalent gas mixture at the pressure corresponding to a tissue target with a diameter of $3 \mu \mathrm{m}$. The counter wall thickness corresponds to about $10 \mathrm{~mm}$ of tissue. The NAUSICAA is equipped with a logarithmic amplifier, it measures directly the linear energy between 0.15 and $1500 \mathrm{keV} / \mu \mathrm{m}$. Continuous data acquisition is performed. Data are compacted in 200 logarithmic intervals from 4096 ADC channels. Dose equivalents are calculated using conversion factors from ICRP 21 recommendations [9]. Event spectra, doses and dose equivalents in low and hight LET (high: $\geq 3.5 \mathrm{keV} / \mu \mathrm{m}$ ) are available as an output computer information.

The instrument is calibrated with a ${ }^{60} \mathrm{Co}$ photon source for low linear energy transfer (LET) region, and in the field of bare ${ }^{252} \mathrm{Cf}$ neutron source for high LET region. The immediate performance of the equipment is regularly controlled by means of an internal ${ }^{244} \mathrm{Cm}$ alpha particle source.

The NM2 moderator-type neutron dose equivalent meter is commercialy available from Nuclear Enterprises. It is an Anderson-Braun type of counter [1] with a BF3 proportional tube. The equipment permits to measure neutron dose equivalent rates averaged through the integration times $3.8,38$ and 380 s., from $\sim 0.1$ to $10^{4} \mu \mathrm{Sv} / \mathrm{h}$.

A radiometer $R P 114$ has been built to measure environmental doses and dose rates of low LET radiation [12]. It is based on a set of GM counters, they can measure low LET dose rates from $\sim 0.1$ to $10^{5} \mu \mathrm{Sv} / \mathrm{h}$.

Two individual electronic personal dosemeters have also been used on board, both are dedicated to measure the dose equivalents from low LET radiation. One of them, DMC90, commercialy available from Merlin-Gérin, France (now MGP-Instruments), is based on a small Si-diode, another one D222 available from ZMA Ostrov, Czech republic [12] is based on a small GM-counter. The minimum reading signal for both of them is $1 \mu \mathrm{Sv}$. 


\section{b) Passive detectors}

Thermoluminescent $\mathrm{CaSO}_{4}: \mathrm{Dy}$ detectors prepared in the laboratory have been used for passive measurements of low LET radiation. The lowest detectable dose for this material is about $2 \mu \mathrm{Sv}[4]$.

Track etch detectors (TED) CR-39, available from Pershore, UK, have been used to measure high LET primary and secondary particles aboard, some recent details about its treatment are presented in [23].

Bubble damage neutron detectors (BDNDs') available are from BTI, Chalk River, Canada [7]. Two type of BDNDs' have been used: thermally compensated PND and BD100R without temperature compensation. The samples used, with a $100 \mathrm{keV}$ neutron energy threshold, presented a nominal sensitivity of 1 bubble per $1 \mu \mathrm{Sv}$ for AmBe neutrons.

TLDs' as well as RP114, DMC-90 and D222 have been calibrated with ${ }^{60} \mathrm{Co}$ photons; TEDs', BDNDs', and NM2 with ${ }^{252}$ Cf neutrons. For both radiations the response has been expressed in terms of ambient dose equivalent $H^{*}(10)$ with ICRP 21 quality factors [9].

\subsection{Flight routes}

Two on-board studies are presented and discussed in this work:

- the study performed during the flight Prague-Montreal (PRG-YMC) on February 4, 1995, and

- the study performed during the flight Montreal-Prague (YMC-PRG) on February 11, 1995.

On-board flight data for both routes have been available; let us remind the geographical positions of Prague $\left(50^{\circ} \mathrm{N}, 11^{\circ} \mathrm{E}\right)$ and Montreal $\left(47^{\circ} \mathrm{N}, 74^{\circ} \mathrm{W}\right)$.

\section{Results}

\subsection{NAUSICAA TEPC counter results}

The flight to Montreal (04.02.1995) has been realised at two flight altitudes, 31000 feet (2.5 hours) and 35000 feet (5.5 hours), the return flight to Prague (11.02.1995) again at two flight altitudes, 33000 (3.75 hours) and 37000 feet ( 2 hours). The measurements with NAUSICAA have been repeated with a 10 min reading cycle. We have observed that general microdosimetric characteristics do not depend on the flight altitude, the average value of the total quality factor is equal to $(1.80 \pm 0.12)$, the quality factor in high LET region to $(6.40 \pm 0.47)$ and the average lineal event value to $(0.438 \pm 0.010) \mathrm{keV} / \mu \mathrm{m}$. As far as the lineal event spectra are concerned their shapes have also been very similar for all flight altitudes, the spectra integrated over all altitudes and all measurements are presented in Figure 1. One can see there the typical struc- 
ture composed from low LET components (mostly below $10 \mathrm{keV} / \mu \mathrm{m}$ ) and high LET neutron components (peaked at $100 \mathrm{keV} / \mu \mathrm{m}$ ).
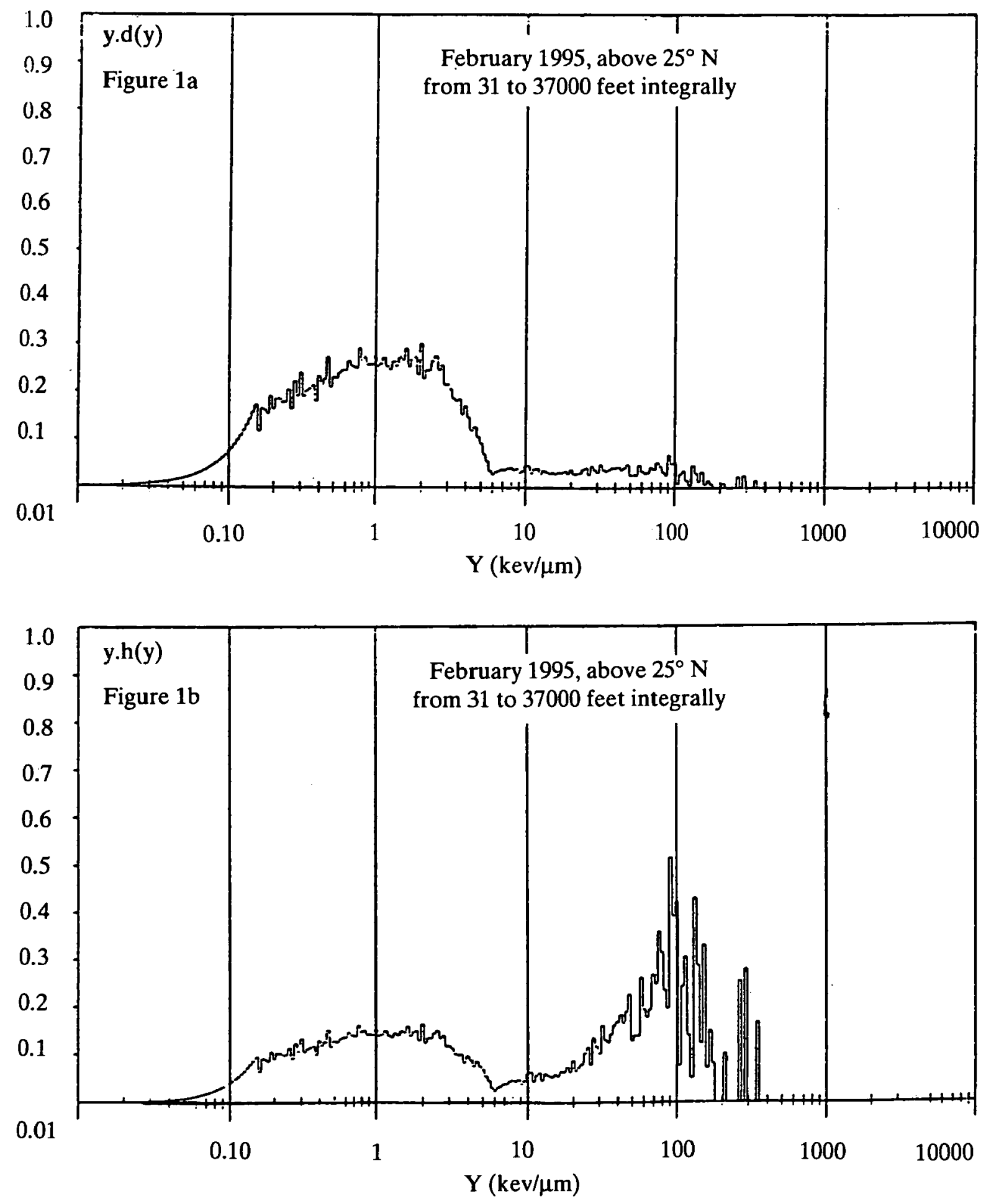

Fig. 1 - Relative absorbed dose distribution (a) and relative dose equivalent distribution (b) over all measurements.

Distribution de la dose absorbée relative (a) et de l'équivalent de dose relatif (b) sur l'ensemble des mesures. 
As far as the general level of exposure is concerned, all values measured by NAUSICAA increase regularly with flight altitude being closely constant at a constant flight level. The results obtained are presented in Table I with the statistical deviation for the average of $10 \mathrm{~min}$ interval measurements. One can see there the known variations in statistical reliability of measurements discussed already in [15]. The average relative standard deviation of an individual measurement is only 0.083 for count rate, it gradually increases to 0.12 for $H_{\text {low }}$, 0.19 for $D_{\text {high }}$, and to 0.44 for $H_{\text {high }}$. The uncertainty of the average values decreases to about 0.11 for $H_{\text {high }}$ up to 0.023 for the count rate. It is statistically well founded because the number of counts with events above $10 \mathrm{keV} / \mu \mathrm{m}$ represents only about $0.1 \%$ of the total number. Consequently, the statistical uncertainty of dose and dose equivalent readings is mainly determined by the few events of high lineal energy.

TABLE I

Dosimetric characteristics of radiation fields on board as measured with NAUSICAA TEPC

Caractéristiques dosimétriques du champ de radiation mesuré avec le TEPC NAUSICAA à bord des avions

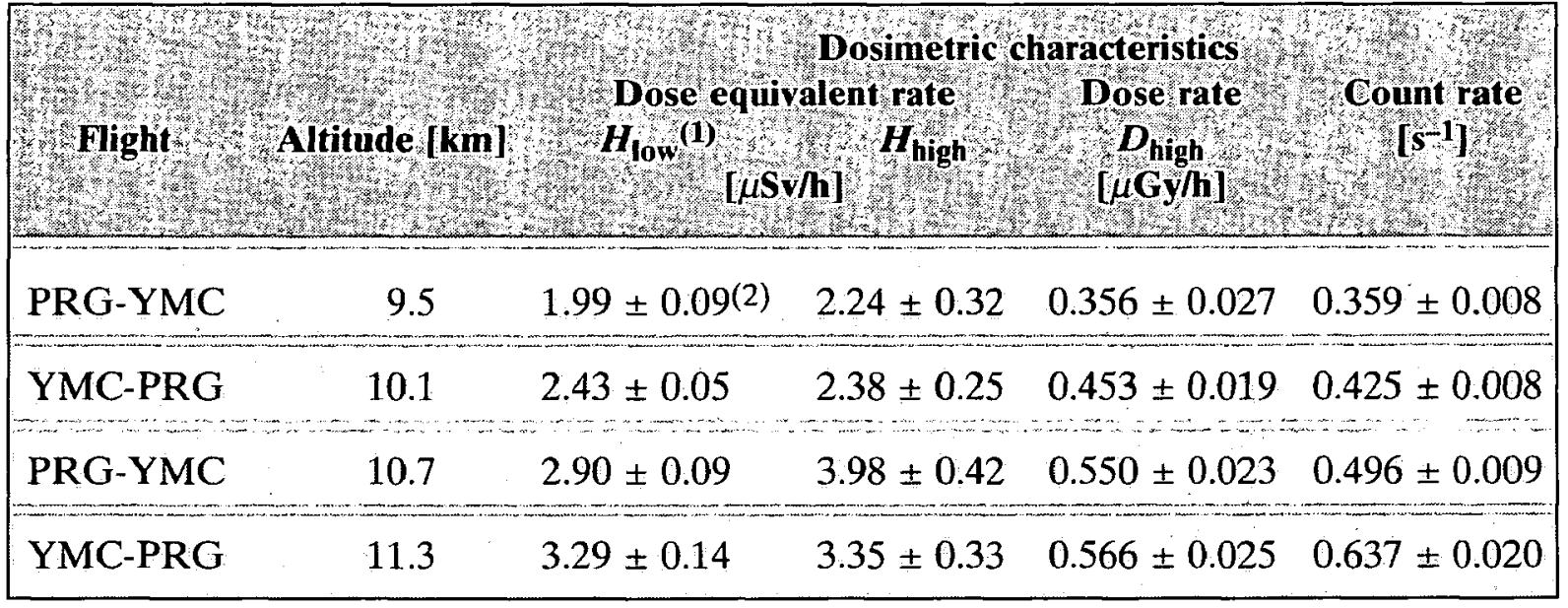

(1) low: $\leq 3.5 \mathrm{keV} / \mu \mathrm{m}$; high $>3.5 \mathrm{keV} / \mu \mathrm{m}$.

(2) one standard deviation of the average value, only statistical uncertainties taken into account.

Let us mention that the count rate and $H_{\text {low }}$ fit very well with linear dependence on flight level, the dependence is not so simple for $H_{\text {high }}$ and $D_{\text {high }}$. However, even in these cases the values obtained through linear fitting differ from the measured ones less than one standard deviation.

\subsection{Exposure levels measured by other instruments}

The results of measurements with other active instruments have also shown that the exposure level is constant at constant flight altitude. The values obtained are presented in Table II. One can see there that the readings of NAUSICAA TEPC for both components of radiation are higher than the readings of 
other active instruments, the difference being much higher for the high LET (neutron) component. The average ratios are equal to $(1.22 \pm 0.04)$ for the low LET component, and to $(2.10 \pm 0.27)$ for the high LET component. These factors agree well with the estimation published in our previous works, i.e. correction factors 1.25 for the low LET and 2.0 for the high LET component $[10,16]$.

TABLE II

Direct average readings of active measuring instruments Moyenne des mesures réalisées avec des détecteurs actifs

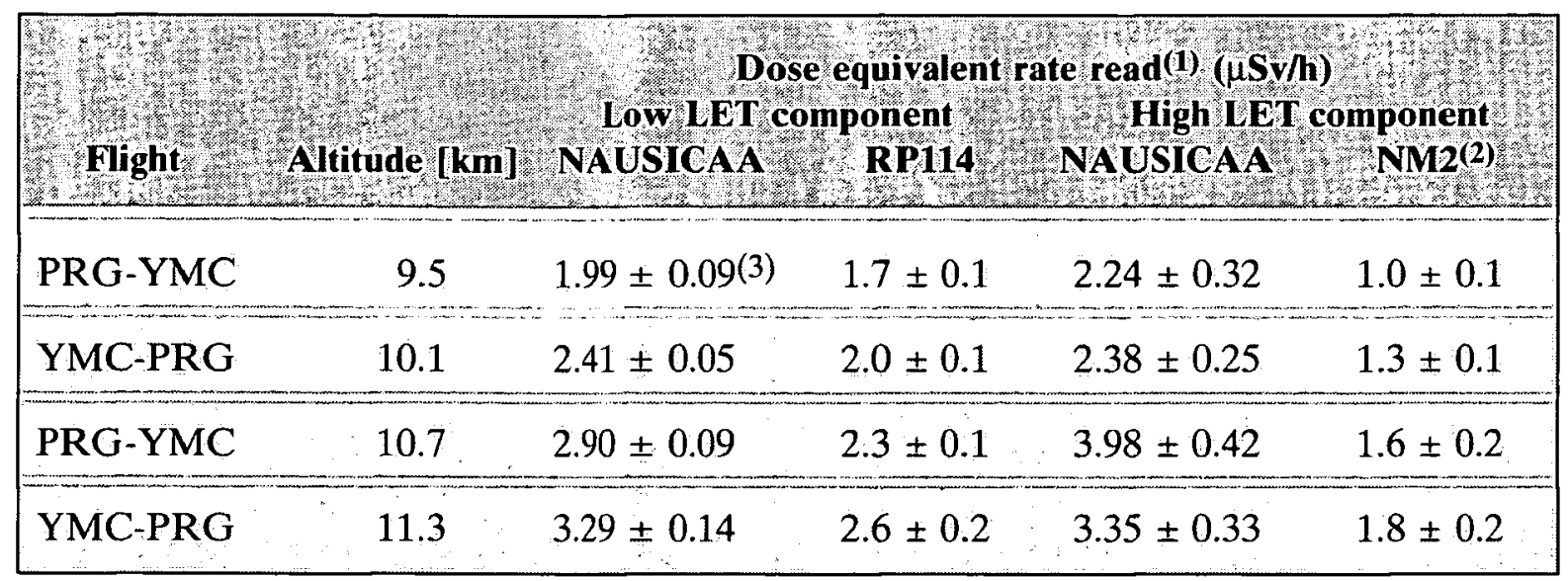

(1) in $H^{*}(10)$ of reference radiation.

(2) results taken from previous measurements during the flights PRG-NYC, comparatively to present RP114 results [20].

(3) one standard deviation of the average value, only statistical uncertainties are taken into account.

\subsection{Integral values of exposure}

Other detectors have made it possible to evaluate directly the integral values of exposure, the flight profiles known have permitted to calculate the integral values of apparent (i.e. in $H^{*}(10)$ of reference radiation) dose equivalents from rate values measured by active instruments. The results obtained are presented in Table III. One can see there that:

1) The values of apparent high LET dose equivalents measured with BDNDs, as seen previously $[10,16]$ and as in CERN reference fields $[6,17]$, are comparable with the moderator type neutron remmeter values; both are clearly lower than the values measured with NAUSICAA TEPC.

2) Quite good agreement is observed between GM based low LET detectors (RP114, D222) and TLDs, theirs readings are a little bit lower than TEPC results. As far as DMC-90 estimation is concerned, it is clearly lower even as compared to GM-based equipment or TLDs. Comparable behaviours have already been observed on the aircraft board [18], in CERN reference fields [17] and by other authors [2]. It is probably connected with the differences in energy transfer constants for high energy radiation and ${ }^{60} \mathrm{Co}$ reference photons. 
TABLE III

Integral values of the apparent dose equivalent Valeurs intégrées de l'équivalent de dose apparent

\begin{tabular}{|c|c|c|c|c|}
\hline \multicolumn{5}{|c|}{ 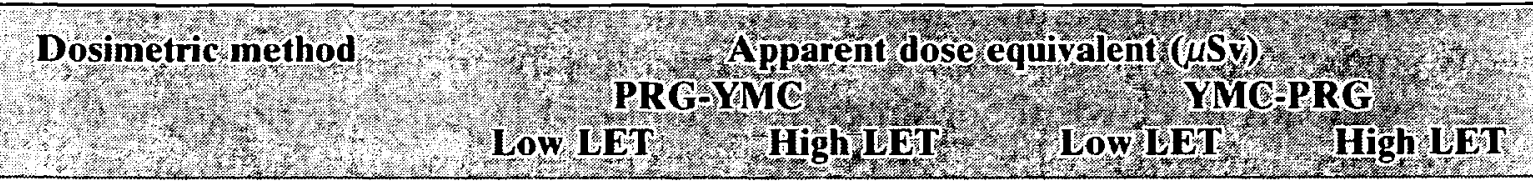 } \\
\hline NAUSICAA-TEPC & $20.9 \pm 0.7^{(2)}$ & $27.3 \pm 3.1$ & $17.5 \pm 0.5$ & $17.0 \pm 1.7$ \\
\hline NM2 & - & $12.3 \pm 2.0$ & - & $9.2 \pm 1.2$ \\
\hline $\begin{array}{r}- \text { PND } \\
- \text { BD } 100 R\end{array}$ & - & $\begin{array}{l}12.8 \pm 2.0 \\
12.3 \pm 2.0\end{array}$ & $\begin{array}{l}- \\
-\end{array}$ & $\begin{aligned} 10.3 & \pm 1.8 \\
6.7 & \pm 1.4\end{aligned}$ \\
\hline RP114 & $16.9 \pm 0.8$ & - & $13.8 \pm 1.0$ & - \\
\hline D222 & $18.9 \pm 0.8$ & - & $13.8 \pm 1.0$ & - \\
\hline DMC90 & $10.0 \pm 1.1$ & - & $7.8 \pm 1.5$ & - \\
\hline TLDs' & - & - & $34 \pm 10^{(1)}$ & - \\
\hline
\end{tabular}

(1) integral value for both flights.

(2) one standard deviation, only statistical uncertainties.

Some additional information can also be deduced from the CR39 TED response. A large surface detector $\left(34 \mathrm{~cm}^{2}\right)$, covered on both sides by polyethylene has been exposed during both flights, a detector of roughly the same surface has been kept in the Prague laboratory as the background. After the flights, both detectors have been etched using a standard procedure, i.e. chemical etching at high temperature followed by electrochemical etching at room temperature [23]. It has been found that the total number of spots in the exposed detector is 2940 , in the background 1790 . The difference corresponds to the track density $(40 \pm 6) \mathrm{cm}^{-2}$. It is not too far from the value observed during the return Prague-New York flight on October 1992, $(28 \pm 5) \mathrm{cm}^{-2}$ [20]. Three types of particles can contribute to this figure, neutrons and high energy protons through their secondary, resp. primary high-energy charged particles. When the apparent ${ }^{252} \mathrm{Cf}$ neutrons dose equivalent measured (see Tab. III) is taken into account, the spot density due to high energy protons would not be higher than $1-2 \mathrm{~cm}^{-2}[19,20]$. If the remaining spot density $\left(\sim 32 \mathrm{~cm}^{-2}\right)$ corresponds to heavy charged particles, their flux would be about $6 \times 10^{-4} \mathrm{~cm}^{-2} \cdot \mathrm{s}^{-1}$. It is too much according to recent theoretical estimation [17]. We do not know the reasons for the effect observed, it cannot be explained by high energy neutrons contributions because the response of CR 39 to them is lower than to ${ }^{252} \mathrm{Cf}$ neutrons. 
F. SPURNÝ et al.

\section{Discussion and conclusions}

The results presented in this work complement the data accumulated in our laboratories for a long time, their main importance consists in the fact that these studies make it possible to compare directly the data obtained many times by means of classical "dosimetry" equipment $[10,16,17,18,20]$ with the results of measuremnts with a TEPC equipment. Moreover such direct comparison could be very fruitful due to the fact that we have had the same possibility with the high energy reference fields at CERN $[6,17,21]$. wing:

The general conclusions from the analysis of all sets of data are the follo-

1) Comparison of relative readings on board and at CERN (top concrete position [6]):

a) The readings of neutron detectors in both fields are relatively very similar; the readings of TEPC equipment being about 2 times as high as the readings for other detectors (NM2, BDND, etc.).

b) The readings of low LET radiation detectors agree very well in both fields, with the exception of the DMC-90 electronic dosemeter with Si-diode. For that detector, the readings represent about 0.6 of readings for other instruments.

c) The relative contribution of low LET radiations aboard is clearly more important than in CERN fields. While aboard it roughly represents 0.5 of total $H^{*}(10)$, in the CERN reference fields obviously about $25 \%$, depending, however, seriously on the variations in muon background $[6,21]$.

2) Level of aircraft exposures during non-equatorial flights:

a) Our experiments have proved that TEPC instruments could be used as very good reference instruments to characterise the level of exposure on board the aircraft. Nevertheless, it does not seem that it can be recommended as a routine monitor. First, its mechanical fragility and electromagnetic sensitivity lead to outliners, particularly at the taking-off period of flight (vibrations, radar, etc.), always leading to serious overestimations of exposure levels. Secondly, the statistical variations of readings (see Tab. I for $10 \mathrm{~min}$ reading cycles) are inevitable and psychologically inconvenient.

b) We have also proved the independence of the exposure level with the geographical position during the flights from central Europe to the central part of North America $[15,16,20]$, i.e. for latitudes above $50^{\circ} \mathrm{N}$.

c) We have also obtained additional data on the influence of flight altitude on the exposure level. We have found out again that, when statistical reliability is taken into account, the total dose equivalent increases about $15 \%$ for each 2000 feet of flight altitude [22].

d) The analysis of results has again confirmed that the correction factors to be used for "classical" dosimetry equipment and detectors, i.e. 1.25 for low LET and 2.0 for high LET components of the field $[10,16]$ are reasonable; corrected data are presented in Table IV. 
e) As far as the solar cycle influence is concerned, the data presented in this report are comparable with the results obtained in October 1992, about $15 \%$ higher than those measured in April 1991. It agrees very well with data available from cosmic radiation monitor stations at the High Tatras, Slovakia, and Calgary, Canada (ratio of monitor countings $1.14 \pm 0.03$ ).

f) We would want again to emphasise the possible variation of the total dose equivalent values for the same flight route (Tab. IV). In the case of the present flights, the strong wind during OK101 flight shortened the time of flight from about 8 up to 5.75 hours, and thus led to a much lower total exposure.

TABLE IV

Integral values of the ambient dose equivalents

- best estimates using the correction factors mentioned

Valeurs intégrées de l'équivalent de dose ambiant

- meilleure estimation en utilisant les facteurs de correction mentionnés

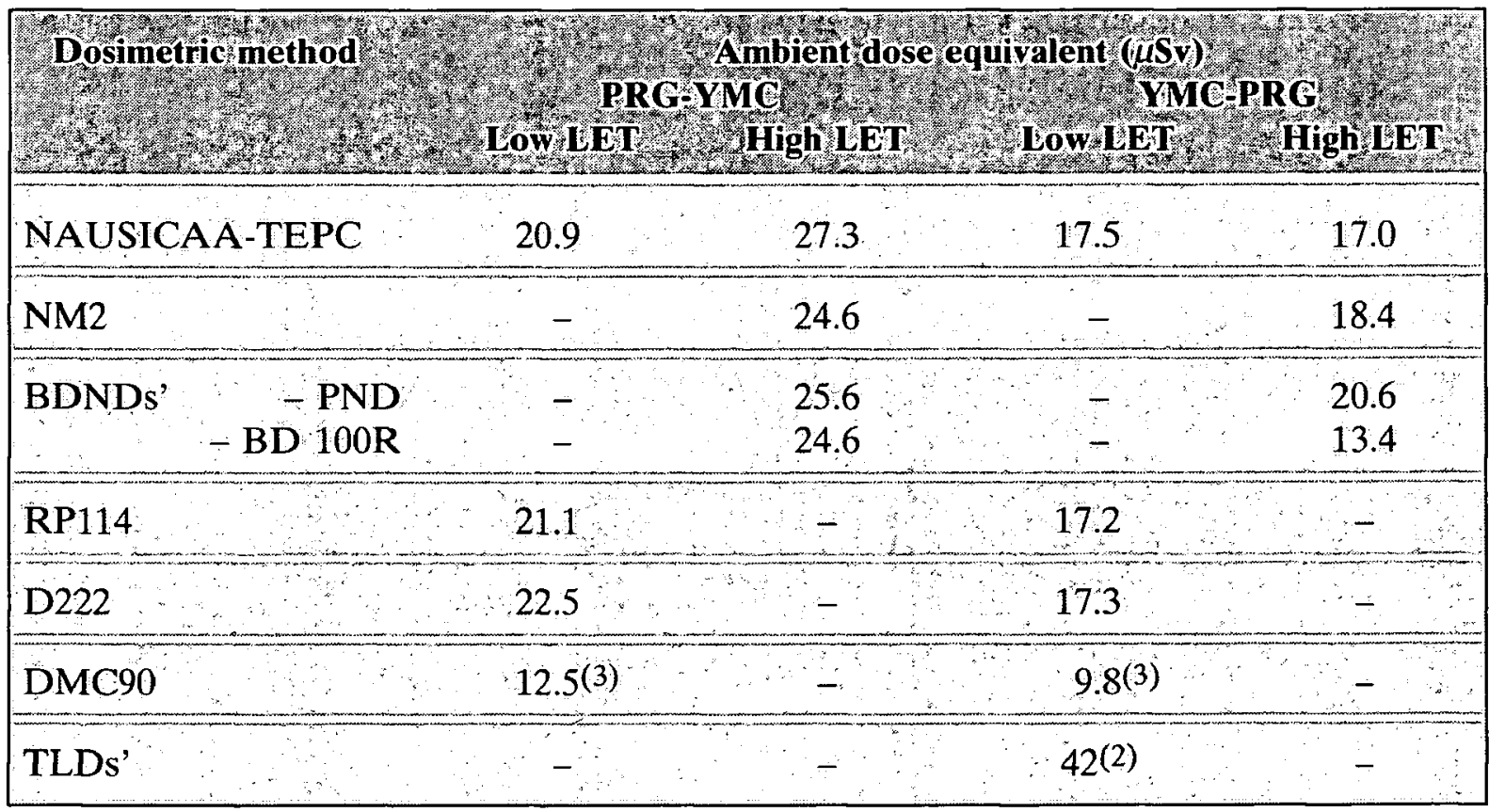

(1) the systematic uncertainty is estimated to $\pm 8 \%$ for the low LET component, $\pm 15 \%$ for the high

LET component; for statistical uncertainties see Table III.

(2) for both flights together.

(3) DMC90 underestimates the exposure level (see text).

\section{REFERENCES}

[1] ANDERSON L.O., BRAUN J.A. - A neutron rem counter. Nucleonik, 1964, 6, 237241.

[2] BARTLETT D. - Private communication, NRPB, Didcot, UK.

[3] BOUISSET P., NGUYEN V.D., KERLAU G., LEBARON L., PARMENTIER N. - Description de l'instrument Nausicaa conçu pour effectuer des mesures instantanées de $H, D$ et du spectre de TLE en champs complexes. In : IRPA 8 , Montréal, mai 1992, 463-466. 
F. SPURNÝ et al.

[4] GueleV M.G., MISChEV I.T., BURGKHARDT B., PIESCH E. - A two-element $\mathrm{CaSO}_{4}$ :Dy dosemeter for environmental monitoring. Radiat. Prot. Dosim., 1994, 51, 35-40.

[5] HENRICH W., O'SUllivaN D. - Private communication, Siegen University, FRG, Dublin University, Ireland.

[6] HÖFERT M., STEVENSON G.S. - The CERN-CEC high energy reference field facility. In $: 8$ th International conference on radiation shielding, Arlington, Texas, April 1994. La Grange Park, Ill. : American nuclear society, 1995, vol. 2, 635-642.

[7] ING H. - Bubble technology industries report, Chalk River, Canada, 1991.

[8] INTERNATIONAL COMMISSION ON RADIOLOGICAL PROTECTION (ICRP) - Recommendations... (ICRP publication 60). Ann. ICRP, 1991, 21 ( $\mathbf{n}^{\circ} 1-3$ ).

[9] INTERNATIONAL COMMISSION ON RADIOLOGICAL PROTECTION (ICRP) - Data for protection against external radiation (ICRP publication 21). Oxford : Pergamon press, 1971 (remplacé par ICRP publication 51).

[10] MICHALIK V., SPURNY F., PERNICKA F., NGUYEN V.D. - Some aspects of the exposure of aircraft crew members to cosmic radiation. Radiat. Prot. Dosim., 1994, 54, 255-258.

[11] NGUYEN V.D., LUCCIONI C., PARMENTIER N. - Average quality factor and dose equivalent meter based on microdosimetry technique. Radiat. Prot. Dosim., $1985,10,277-285$.

[12] Radiometer RP114, description manual. Ostrov nad Ohri, Czech republik, 1992.

[13] REITZ G., SCHRAUBE K., SHAW K., Eds. - Radiation exposures of civil aircrew. Radiat. Prot. Dosim., 1993, $48\left(\mathrm{n}^{\circ} 1\right)$.

[14] SCHRAUBE H. - Private communication. GSF, FRG.

[15] SCHUMACHER H., SCHREWE U.J. - Dose equivalent measurements on board civil aircraft. PTB-N-13, PTB Bericht, Braunschweig, 1993.

[16] SPURNY F., VOTOCKOVA I. - Radiation exposure of aircrew and passengers during some CSA commercial flights. In : Proceedings of the 26th Jahrestagung des Fachverbandes für Strahlenschutz, Karlsruhe, 1994, vol. 2, 549-553.

[17] SPURNY F., VOTOCKOVA I., TUREK K. - Equipment and detectors calibration behind shielding of CERN high energy particle accelerator SPSII, May 1994. Report IRD AS CR 391/94, Prague 1994.

[18] SPURNY F., VOTOCKOVA I. - Aircrew and passenger exposures during some other european flights (1994-1995). Report DRD NPI AS CR 402/95, Prague, 1995.

[19] SPURNY F. - Dosimetry of neutrons and high energy particles with nuclear track detectors, presented at the 17th ICNTS, Dubna, August 1994. Nucl. Tracks Radiat. Meas., 1994, 25, 429-436.

[20] SPURNY F., VOTOCKOVA I. - Aircrew and passenger exposures during OK flights OK 600/601, October 1992. Report IRD CAS 359/92, Prague, 1992.

[21] SPURNY F., NGUYEN V.D., BOTTOLIER-DEPOIS J.F., VOTOCKOVA I., TUREK K. - Response of different dosimetry systems in high energy calibration fields at SPS accelerator at CERN. Bezpecnost Jad. Energ. (to be published).

[22] SPURNY F., HEINRICH W., REITZ G. - Exposure of aircrew to cosmic radiation. EURADOS working group 11 (to be published).

[23] TUREK K., SPURNY F., ALBERTS W.G. - On the optimisation of the etching of CR39 as fast neutron dosemeter. Nucl. Tracks Radiat. Meas., 1993, 21, 299-302. 